\title{
Uneven Evolution of Microstructure, Magnetic Properties and Coercivity Mechanism of Mo-Substituted Nd-Ce-Fe-B Alloys
}

\author{
Li-Li Zhang ${ }^{1}$ - Jie Song ${ }^{1}$ - Sajjad Ur Rehman ${ }^{1} \cdot$ Jia-Jie Li ${ }^{1}$ - Lei Wang ${ }^{1,2} \cdot$ Mu-Nan Yang ${ }^{1} \cdot$ Ren-Hui Liu ${ }^{1}$. \\ Qing-Zheng Jiang ${ }^{1} \cdot$ Zhen-Chen Zhong $^{1}$
}

Received: 12 January 2020 / Revised: 31 March 2020 / Published online: 7 July 2020

(c) The Chinese Society for Metals (CSM) and Springer-Verlag GmbH Germany, part of Springer Nature 2020

\begin{abstract}
The purpose of this paper is to study the influence of Mo addition on the phase morphologies, microstructures and magnetic properties of the designated alloys. It is found out that the coercivity $H_{\mathrm{cj}}$ increases unevenly from $12.2 \mathrm{kOe}$ for $\left(\mathrm{Nd}_{0.8} \mathrm{Ce}_{0.2}\right)_{13} \mathrm{Fe}_{82} \mathrm{~B}_{5}$ to the maximum value of $13.3 \mathrm{kOe}$ for $\left(\mathrm{Nd}_{0.8} \mathrm{Ce}_{0.2}\right)_{13} \mathrm{Fe}_{80} \mathrm{~B}_{5} \mathrm{Mo}_{2}$. The transmission electron microscopy images demonstrate that the grain size decreases with the addition of Mo, which indicates that Mo has grain refinement effect. The correlative analysis gives rise to the conclusion that the coercivity mechanism of the investigated alloys is dominated by pinning type. All in all, the enhancement of the magnetic properties is mainly attributed to the synergistic impact of grain refinement, pinning effects and the microstructural homogenization. The research may shed light on the potential development and application of rare earth-based counterpart magnets.
\end{abstract}

Keywords Mo-doped Nd-Ce-Fe-B alloy $\cdot$ Magnetic properties $\cdot$ Melt-spun ribbons $\cdot$ Microstructure $\cdot$ Coercivity mechanism

\section{Introduction}

$\mathrm{NdFeB}$ magnets are rare earth permanent magnetic materials with the highest maximum energy product $(\mathrm{BH})_{\max }$ and best comprehensive magnetic properties, which have been widely used in machinery, electronics, wind generators, computers and other fields [1-3]. Heavy rare earth elements (HREE), such as Dy and $\mathrm{Tb}$, are usually added to ensure high coercive force because HREE usually have high magnetocrystalline anisotropy field $H_{\mathrm{A}}[4,5]$. The huge consumption of the key rare earth (RE) elements such as Pr, $\mathrm{Nd}$, Dy and $\mathrm{Tb}$ leads to their shortage and the sharp price fluctuation [6]. Therefore, it is crucial to study the mechanisms of the

Available online at http://link.springer.com/journal/40195.

Zhen-Chen Zhong zczhong2013@163.com

1 Jiangxi Key Laboratory for Rare Earth Magnetic Materials and Devices/Institute for Rare Earth Magnetic Materials and Devices, Jiangxi University of Science and Technology, Ganzhou 341000, China

2 Fujian Changting Golden Gragon Rare-Earth Co., Ltd, Changting 366300, China magnets with cheaper RE elements while maintaining the performance of sintered $\mathrm{NdFeB}$ permanent magnets. The previous studies showed that the room-temperature coercivity of CeFeB-based alloys may be improved effectively with a proper Hf doping [7]. Ta is employed to enhance the coercivity by refining the microstructure in $\mathrm{Ce}_{17} \mathrm{Fe}_{78-x} \mathrm{Ta}_{x} \mathrm{~B}_{6}$ alloys [8]. The addition of $\mathrm{Zr}$ strengthens the exchange coupling effect, thereby increasing the magnetic properties of the $\mathrm{Ce}_{17} \mathrm{Fe}_{77.5} \mathrm{~B}_{6} \mathrm{Zr}_{0.5}$ alloys [9]. $\mathrm{NdCu}$ is used to improve the magnetic properties at room and elevated temperatures, and the thermal stabilities of the $\mathrm{CeFeB}$-based spark plasma sintered magnets [10]. Co-doping improves the Curie temperature $T_{\mathrm{c}}$ of the $\mathrm{CeFeB}$ alloys [11]. There are many economical and technological advantages for the partial substitution of $\mathrm{Ce}$ for Nd. Most strikingly, this type of replacement of critical RE elements with cheaper element Ce can reduce the production cost of magnets and is useful for the balanced utilization of rare earth resources though the magnetic properties and Curie temperature decreased slightly [12-17].

There are usually two traditional ways to increase the Curie temperature of commercial magnets: One is to add Co element to replace $\mathrm{Fe}$ atoms, and another is to add HREE such as Dy and $\mathrm{Tb}$ to increase the magnetocrystalline anisotropy field, thereby achieving the purpose of improving 
the coercivity to increase $T_{\mathrm{c}}$ indirectly $[4,5]$. Furthermore, elements with low and high melting points are also added to improve the microstructure and morphology in order to enhance the extrinsic magnetic properties of these alloys. The controlled substitution of low melting point elements such as $\mathrm{Al}, \mathrm{Cu}, \mathrm{Ge}$ and $\mathrm{Ga}$ has been reported to improve the coercivity of $\mathrm{Nd}-\mathrm{Fe}-\mathrm{B}$-type alloys [18-20]. On the other hand, the high melting point elements such as $\mathrm{Hf}, \mathrm{Ta}$, $\mathrm{Zr}$ and $\mathrm{Nb}$ have also been reported to refine the grains of nanocrystalline magnets and hence improve the magnetic properties [21, 22]. It was claimed that Mo element controls the crystallization during rapid solidification leading to grain refinement, uniform microstructure and ultimately improves the magnetic properties of $\mathrm{Nd}_{17} \mathrm{Fe}_{73} \mathrm{~B}_{7} \mathrm{Ga}_{1} \mathrm{Mo}_{2}$ alloy [23]. By optimizing the ratio of Mo content and $\mathrm{B}$ content, Hirosawa et al. found out that a small amount addition of Mo improved the intrinsic coercivity of Nd-Dy-Fe-Co-B sintered alloys [24]. A small addition of Mo was also proved to enhance the intrinsic coercive force up to $19,400 \mathrm{Oe}$, and $H_{\mathrm{k}}=12,000$ Oe $\left(H_{\mathrm{k}}\right.$ : Knee Point Coercivity, the magnetic field corresponding to $J_{\mathrm{i}}=0.9$ or $0.8 B_{\mathrm{r}}$ on the demagnetization curve) in $\mathrm{Nd}-\mathrm{Fe}-\mathrm{Co}-\mathrm{B}-\mathrm{Mo}$ alloys [25]. Rieger et al. revealed that the additive Mo improved the coercive field, reduced the average grain size significantly, and narrowed the grain size distribution [26]. Zhou and Wang found out that adding 1.5\% (mass fraction) Mo, the intrinsic coercivity of $\mathrm{Nd}_{22} \mathrm{Fe}_{71} \mathrm{~B}_{7} / \mathrm{Mo} \mathrm{sin}$ tered magnet was enhanced [27]. The role of $\mathrm{Mo}$ in $\mathrm{NdFeB}$ has been studied, but the relevant literature about the application of Mo in Ce-based materials has not been reported. Therefore, we desire to effectively refine grains and improve magnetic properties by adding a small amount of high melting point element Mo, which helps to retain the magnetic properties deteriorated due to substitution of $\mathrm{Nd}$ by Ce. It is reported in the literature $[28,29]$ that the optimal composition of the NdFeB alloy is $\mathrm{Nd}_{13} \mathrm{Fe}_{82} \mathrm{~B}_{5}$ and $20 \%$ Ce substitution of $\mathrm{Nd}$ in $\mathrm{Nd}_{2} \mathrm{Fe}_{14} \mathrm{~B}$ can enhance the coercivity [12, 30, 31]. Therefore, the $\left(\mathrm{Nd}_{0.8} \mathrm{Ce}_{0.2}\right)_{13} \mathrm{Fe}_{82-x} \mathrm{~B}_{5} \mathrm{Mo}_{x}$ was selected for systematic investigation. We have studied methodically the effect of the Mo addition on the phase composition, grain boundary modification, magnetic performance, microstructure and coercivity mechanism of $\left(\mathrm{Nd}_{0.8} \mathrm{Ce}_{0.2}\right)_{13} \mathrm{Fe}_{82-x} \mathrm{~B}_{5} \mathrm{Mo}_{x}$ $(x=0,1.0,2.0,3.0)$ alloys fabricated by rapid solidification method. Focused research in this paper, however, is the uneven magnetic properties and coercivity mechanism of the Mo-substituted nanocrystalline $\mathrm{Nd}-\mathrm{Ce}-\mathrm{Fe}-\mathrm{B}$ alloys.

\section{Experimental}

The alloys with the nominal composition of $\left(\mathrm{Nd}_{0.8} \mathrm{Ce}_{0.2}\right)_{13} \mathrm{Fe}_{82-x} \mathrm{~B}_{5} \mathrm{Mo}_{x}(x=0,1.0,2.0,3.0$ at $\%)$ were manufactured by the arc melting method under argon atmosphere. The purity of the raw materials $\mathrm{Nd}, \mathrm{Ce}, \mathrm{Fe}, \mathrm{B}$ and Mo is higher than $99.9 \%$, and the melting is performed at least 5 times to ensure the uniform mixing of the components. The ingots were broken into pieces (4-6 g) and placed into a quartz tube with a bottom opening diameter of $0.7-1.0 \mathrm{~mm}$. The distance between the bottom of the quartz tube and the surface of the $\mathrm{Cu}$ crucible was about $2-4 \mathrm{~mm}$. The alloys were made under the Ar atmosphere, and the optimum wheel speed was $15-25 \mathrm{~m} / \mathrm{s}$. The phase compositions of the alloys were examined by X-ray diffraction (XRD, PANAlytical) applying monochromatic $\mathrm{Cu} K_{\alpha}$ radiation. The magnetic properties of the alloys were tested by a vibrating sample magnetometer (VSM) in a physical property measurement system (PPMS, Quantum Design Co., USA). A maximum magnetic field of $5.0 \mathrm{~T}$ was applied for obtaining the $M-H$ curves. The microstructure observation was performed by transmission electron microscopy (TEM, Tecnai G2 F20).

\section{Results and Discussion}

\subsection{Effect of Mo on the Phase Structure}

Figure 1 shows the XRD patterns for the $\left(\mathrm{Nd}_{0.8} \mathrm{Ce}_{0.2}\right)_{13} \mathrm{Fe}_{82-x} \mathrm{~B}_{5} \mathrm{Mo}_{x}$ alloys. It can be seen from Fig. 1 that the diffraction peaks mainly consist of two phases: 2:14:1 main phase and $\alpha$-Fe soft magnetic phase. The peaks of main phase and $\alpha$-Fe phase become weakened and widened after adding Mo, which indicates that defects or internal stress probably exists or grain size decreases with Mo addition [22]. It is inferred by the XRD patterns that the addition of Mo suppresses the formation of $\alpha$-Fe phase. However, Mo or Mo compounds were not detected in the XRD patterns, which was probably due to small amount of Mo content. In order to explore whether Mo enters into the main phase to replace Fe sites, we calculated the crystal lattice parameters and the cell volume by full-spectrum fitting using Jade 6.0 software. If Mo atoms enter into the main phase to substitute $\mathrm{Fe}$ atoms, the crystal lattice parameters would increase, the cell volume

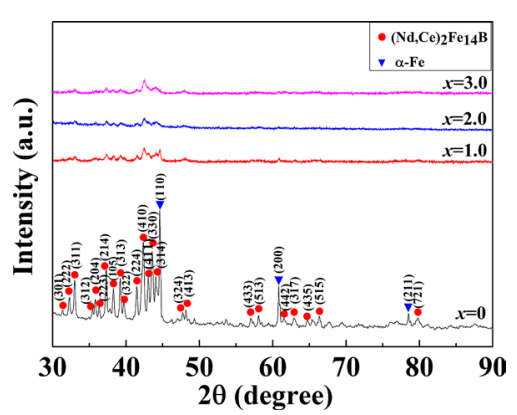

Fig. 1 XRD patterns for $\left(\mathrm{Nd}_{0.8} \mathrm{Ce}_{0.2}\right)_{13} \mathrm{Fe}_{82-x} \mathrm{~B}_{5} \mathrm{Mo}_{x}(x=0,1.0,2.0$, 3.0) alloys 
Table 1 Lattice parameters of the main phases of $\left(\mathrm{Nd}_{0.8} \mathrm{Ce}_{0.2}\right){ }_{13} \mathrm{Fe}_{82-x} \mathrm{~B}_{5} \mathrm{Mo}_{x}(x=0,1.0,2.0,3.0)$ alloys

\begin{tabular}{llll}
\hline$X($ at $\%)$ & $A(\AA)$ & $C(\AA)$ & $V\left(\AA^{3}\right)$ \\
\hline 0 & 8.80105 & 12.18157 & 943.57 \\
1.0 & 8.78633 & 12.18252 & 940.49 \\
2.0 & 8.78837 & 12.17314 & 940.20 \\
3.0 & 8.78876 & 12.20638 & 942.85 \\
\hline
\end{tabular}

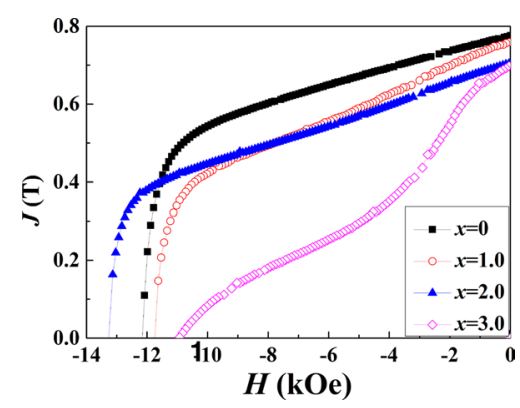

Fig. 2 Demagnetization curves of the $\left(\mathrm{Nd}_{0.8} \mathrm{Ce}_{0.2}\right)_{13} \mathrm{Fe}_{82-x} \mathrm{~B}_{5} \mathrm{Mo}_{x}$ $(x=0,1.0,2.0,3.0)$ alloys

would expand and the diffraction peak would shift to the left side according to the Bragg Equation $2 d \sin \theta=n \lambda$ (where the atomic radius of Mo, $d_{\mathrm{Mo}}=1.39 \AA$, and the atomic radius of $\mathrm{Fe}, d_{\mathrm{Fe}}=1.27 \AA$ ). As listed in Table 1 , the crystal lattice parameters and the cell volume do not increase apparently and the diffraction peaks of the main phase do not shift from Fig. 1, which implies that Mo does not enter into the main phase to replace the Fe sites. It is hard to give a conclusive remark on the distribution of Mo in the alloys. However, it is speculated that some of Mo form molybdenum borides and reside at the grain boundaries and triple junctions to act as pinning centers. The fine-sized borides at the grain boundaries and triple junctions cannot be determined by XRD and TEM analysis [32].

\subsection{Magnetic Properties}

Figure 2 displays the demagnetization (second quadrant) curves of the $\left(\mathrm{Nd}_{0.8} \mathrm{Ce}_{0.2}\right)_{13} \mathrm{Fe}_{82-x} \mathrm{~B}_{5} \mathrm{Mo}_{x}(x=0,1.0,2.0$, 3.0) alloys. The squareness of the curves appears good for $x=0-2.0$ at $\%$. When $x=3.0$ at $\%$, the squareness is deteriorated obviously, which may be attributed to the existence of excess non-magnetic phase containing Mo. The intrinsic $H_{\mathrm{cj}}$ increases, while the $J_{\mathrm{r}}$ and the $(\mathrm{BH})_{\max }$ decrease with increasing Mo content. Figure $3 \mathrm{a}-\mathrm{c}$ exhibits clearly the effect of the addition of Mo on the $J_{\mathrm{r}},(\mathrm{BH})_{\max }$ and the $H_{\mathrm{cj}}$. The formation of the non-magnetic phase containing Mo makes a downward tendency of $J_{\mathrm{r}}$ and the $(\mathrm{BH})_{\max }$. The reason may lie in the decrease in the saturation magnetic polarization $J_{\mathrm{s}}$. The $H_{\mathrm{cj}}$ slightly decreases before the content of the addition of Mo reaches 1.0 at\%. Thereafter, $H_{\mathrm{cj}}$ increases with increasing Mo content with the maximum value of 13.3 kOe at $x=2.0$ at $\%$, while the $H_{\mathrm{cj}}$ decreases again with Mo content $x>2.0$ at $\%$. The reason for the first decline may be caused by the abnormal precipitation of the non-magnetic Mo phase. The increase of $H_{\mathrm{cj}}$ in the range of 1.0-2.0 at $\%$ Mo can be attributed to the combined effect of refined grains and the uniform microstructure. The second reduction of $H_{\mathrm{cj}}$ after $x>2.0$ at\% may be because of the excessive nonmagnetic Mo compounds and detrimental microstructure on the grain boundaries and triple junctions.

\subsection{Microstructure Characterization}

The typical TEM images of $\left(\mathrm{Nd}_{0.8} \mathrm{Ce}_{0.2}\right)_{13} \mathrm{Fe}_{82-x} \mathrm{~B}_{5} \mathrm{Mo}_{x}$ alloys with $x=0$, 1.0, 2.0, 3.0 are demonstrated in Fig. 4a-d. After the addition of Mo, the grain size is significantly reduced and it is clearly shown the grain refining effect of Mo element. Based on the TEM images as shown in Fig. 4a-d, we calculated the grain size distribution by using a nano-measure software. Figure 5a-d gives out the calculation results of the maps. The average grain size of the alloys with $x=0,1.0,2.0,3.0$ are $\sim 75 \mathrm{~nm}, \sim 61 \mathrm{~nm}, \sim 30 \mathrm{~nm}$ and $\sim 27 \mathrm{~nm}$, respectively. The average grain size of the alloys decreases with increasing Mo content, which assumes a low solubility in the hard magnetic phase. The precipitates
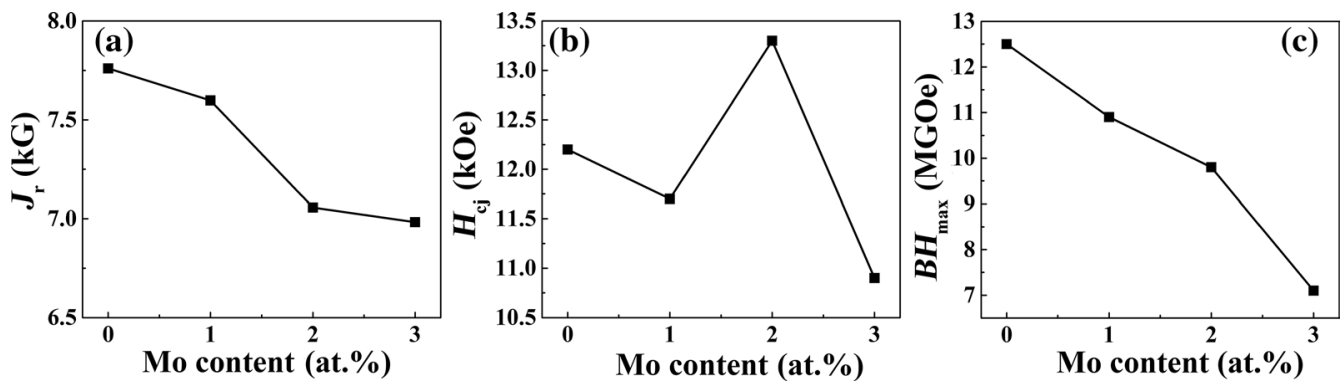

Fig. 3 Magnetic performance as a function of Mo content for $\left(\mathrm{Nd}_{0.8} \mathrm{Ce}_{0.2}\right)_{13} \mathrm{Fe}_{82-x} \mathrm{~B}_{5} \mathrm{Mo}_{x}(x=0,1.0,2.0,3.0)$ alloys 

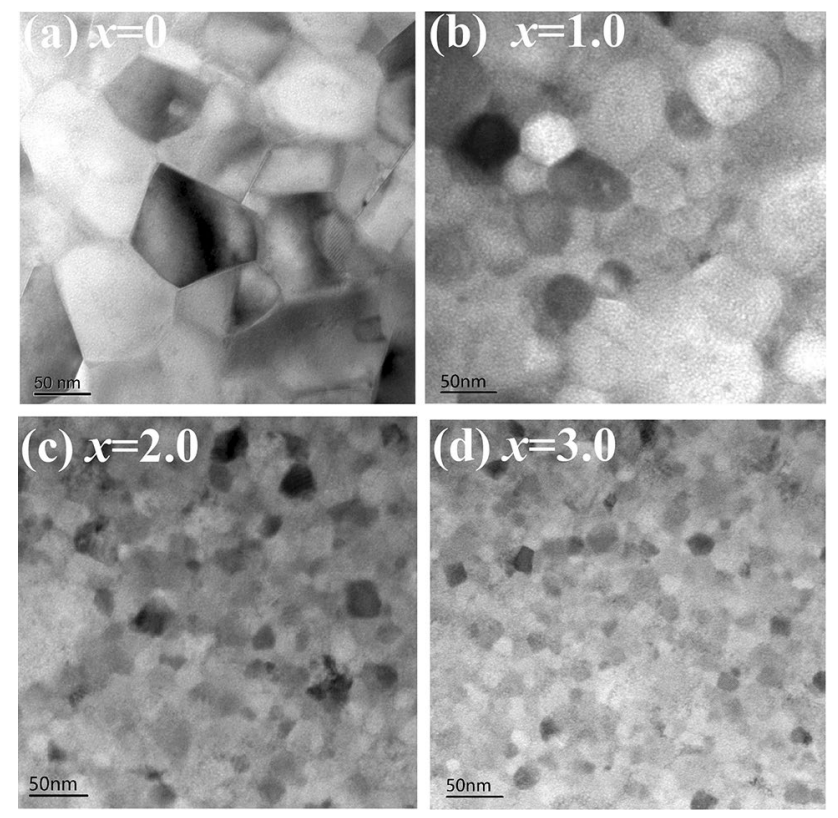

Fig. 4 TEM images of $\left(\mathrm{Nd}_{0.8} \mathrm{Ce}_{0.2}\right)_{13} \mathrm{Fe}_{82-x} \mathrm{~B}_{5} \mathrm{Mo}_{x}$ alloys

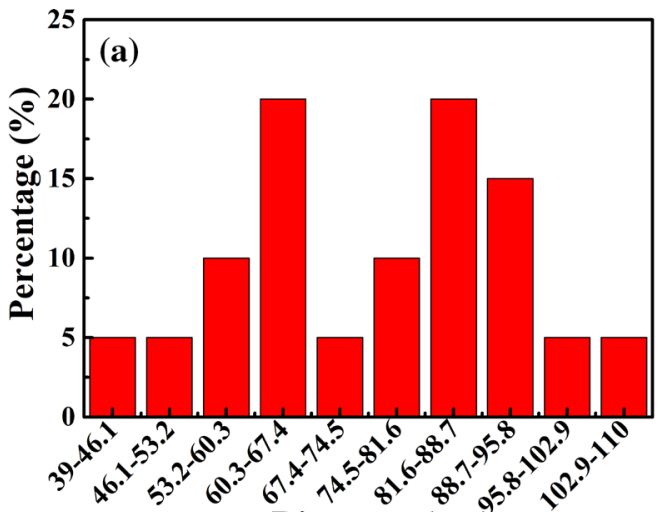

Diameter (nm)

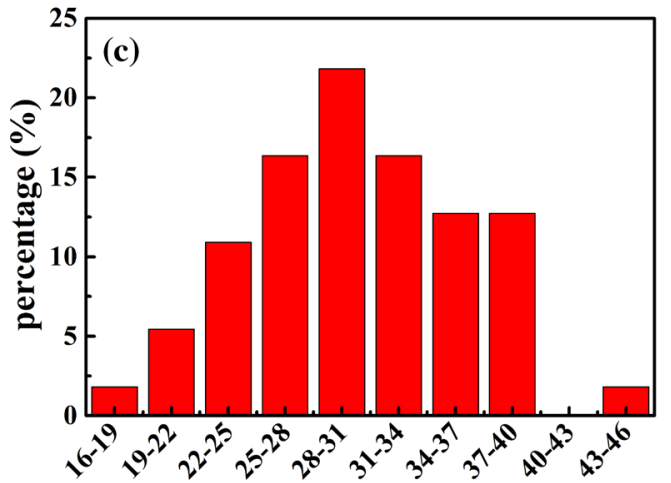

Diameter (nm) may be formed between the main phases, as the pinning centers to suppress the grain growth. Meanwhile, the Mocontaining alloys have more uniformly distributed and more regularly shaped nanoscale grains compared with the Mo-free alloys. By observing the TEM images, it is found out that the original and 1.0 at\% Mo-doping samples have similar grain structure, but XRD patterns are quite different apparently. Adding 1.0 at\% Mo probably increases the internal stress and defects of the alloy, and the grain size is also affected to a certain extent. Now it is noticed that the diffraction peaks of main phase and $\alpha$-Fe phase become weakened and widened. When Mo is above 1.0 at $\%$, the grain size of the alloys are much more affected. The grain size decreases greatly though there are similar intensity signals in XRD patterns for the three Mo-doping samples.

\subsection{Analysis of Coercivity Mechanism}

It can be seen from the initial magnetization curves in Fig. 6 that the saturation magnetization decreases as the Mo content increases in $\left(\mathrm{Nd}_{0.8} \mathrm{Ce}_{0.2}\right)_{13} \mathrm{Fe}_{82-x} \mathrm{~B}_{5} \mathrm{Mo}_{x}$ alloys. The main reason is probably that the formation of non-magnetic phase and the reduction in the soft magnetic phase $(\alpha-\mathrm{Fe})$ lower the saturation magnetization. The type of coercivity mechanism

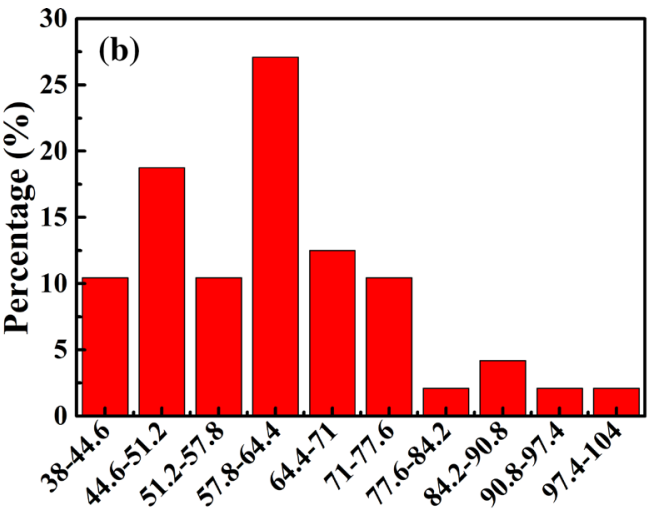

Diameter (nm)

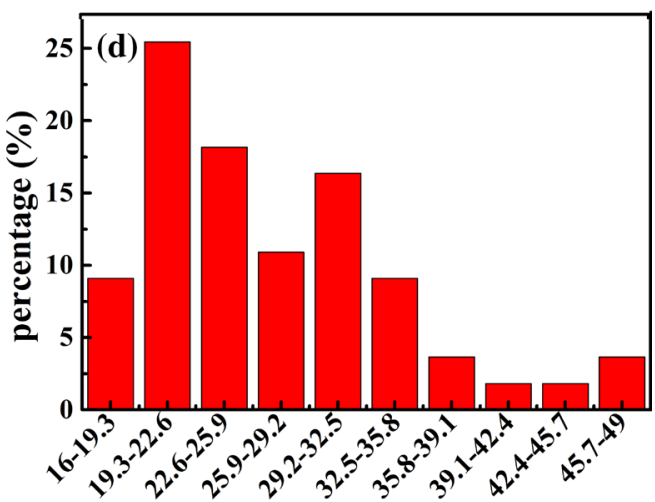

Diameter (nm)

Fig. 5 Calculated particle size distribution maps of $\left(\mathrm{Nd}_{0.8} \mathrm{Ce}_{0.2}\right)_{13} \mathrm{Fe}_{82-x} \mathrm{~B}_{5} \mathrm{Mo}_{x}$ alloys: a $x=0, \mathbf{b} x=1.0, \mathbf{c} x=2.0, \mathbf{d} x=3.0$ 


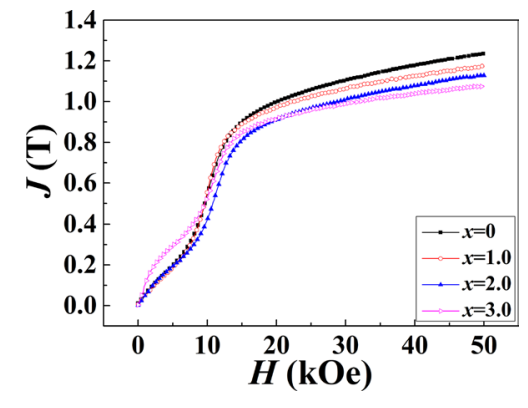

Fig. 6 Virgin curves of $\left(\mathrm{Nd}_{0.8} \mathrm{Ce}_{0.2}\right)_{13} \mathrm{Fe}_{82-x} \mathrm{~B}_{5} \mathrm{Mo}_{x}(x=0,1.0,2.0$, 3.0) alloys

can be initially determined by the shape of the initial magnetization curve. In the alloys with nucleation mechanism, the initial magnetization increases rapidly under a low magnetic field until saturation, the magnetic susceptibility is high, and the magnetization curve is very steep. On the contrary, the initial magnetization of the alloys with pinning mechanism rises very slowly in the initial stage of magnetization. When the applied magnetic field is smaller than the critical field, the magnetization increases very slowly with the magnetic field. However, as the magnetic field exceeds the critical field, the magnetization increases sharply until saturation is obtained $[33,34]$. Figure 6 shows the characteristics of the initial magnetization curves clearly, which indicates that the coercivity mechanisms of the designated alloys may be not monolithic. As the Mo content changes, the coercivity mechanism of the alloys also changes. The initial magnetization curve of $\left(\mathrm{Nd}_{0.8} \mathrm{Ce}_{0.2}\right)_{13} \mathrm{Fe}_{82-x} \mathrm{~B}_{5} \mathrm{Mo}_{x}$ alloy for $x=0-2.0$ at $\%$ ascends slowly in the preliminary stage of the magnetization. Then, the magnetization increases dramatically until saturation when the magnetic field overtakes the critical field. The trend is regular, and their characteristics are consistent with those of the pinning mechanism. Thus, the coercivity mechanism of the alloy for $x=0-2.0$ at $\%$ is inferred to be the pinning mechanism. The initial magnetization of $\left(\mathrm{Nd}_{0.8} \mathrm{Ce}_{0.2}\right)_{13} \mathrm{Fe}_{79} \mathrm{~B}_{5} \mathrm{Mo}_{3}$ increases rapidly under a small magnetic field; then, the magnetization increases smoothly by increasing magnetic field, and finally the magnetization increases sharply until being saturated when the magnetic field exceeds the critical field. Its characteristic appears to be the combination of nucleation mechanisms and pinning mechanisms. Therefore, it is concluded that the coercivity mechanism is a mix of nucleation mechanism and pinning mechanism for the designated alloy.

In order to verify the various coercivity mechanisms, we compared the normalized coercivity $H_{\mathrm{c}}$ and remnant polarization $J_{\mathrm{r}}$ on different applied fields in the minor loops for the four alloys. After being magnetized to saturation on different magnetic fields, the magnetic field reduced to zero, and then, the remanent magnetic polarization $\left(J_{\mathrm{r}}\right)$ can be obtained in the original direction of magnetization. The added reverse magnetic field is defined as the coercivity $\left(H_{\mathrm{c}}\right)$ when the remanent magnetic polarization $\left(J_{\mathrm{r}}\right)$ became zero on different magnetic fields. The remanent magnetic polarization and coercivity are indicated as $J_{\text {rmax }}$ and $H_{\mathrm{cj}}$ under the maximum magnetic field. The ratio of $H_{c}$ and $H_{\mathrm{cj}}$ was compared with the ratio of $J_{\mathrm{r}}$ and $J_{\text {rmax }}$ as shown in Fig. 7. If the $H_{\mathrm{c}} / H_{\mathrm{cj}}$ increases faster than $J_{\mathrm{r}} / J_{\text {rmax }}$ by increasing the strength of applied magnetic field, the coercivity mechanism is believed to be pinning type. The opposite case indicates the nucleation mechanism $[21,22]$. The illustration is the minor hysteresis loop for the alloy at $x=0-3.0$ at $\%$. It is obvious that the $H_{\mathrm{c}} / H_{\mathrm{cj}}$ increases faster than $J_{\mathrm{r}} J J_{\text {rmax }}$ for the alloys at $x=0-2.0$ at $\%$. Therefore, it can be inferred that the alloy at $x=0-2.0$ at $\%$ exhibits pinning type of coercivity mechanism. For the $\left(\mathrm{Nd}_{0.8} \mathrm{Ce}_{0.2}\right)_{13} \mathrm{Fe}_{79} \mathrm{~B}_{5} \mathrm{Mo}_{3}$ alloy, the $H_{\mathrm{c}} / H_{\mathrm{cj}}$ increases slower than $J_{\mathrm{r}} / J_{\mathrm{rmax}}$ in the initial stage, and then, the increase of $H_{\mathrm{c}} / H_{\mathrm{cj}}$ exceeds $J_{\mathrm{r}} / J_{\mathrm{rmax}}$. It can be deduced that both pinning and nucleation mechanisms may exist for the investigated alloy, which is in agreement with the results of the initial magnetization analysis.

\section{Conclusion}

The effects of Mo on the phase structure, magnetic properties, microstructures and coercivity mechanism of the designated alloys were investigated methodically. It is shown by XRD patterns that the alloys mainly consist of two phases: $(\mathrm{Nd}, \mathrm{Ce})_{2} \mathrm{Fe}_{14} \mathrm{~B}$ main phase and $\alpha$-Fe soft magnetic phase being reduced with increasing Mo content quantitatively. The calculated crystal lattice parameters and the cell volume are not increased, and the diffraction peaks of the main phases are not shifted to the left, which imply that Mo element does not enter into the 2:14:1 main phase to replace $\mathrm{Fe}$ element. The coercivity $H_{\mathrm{cj}}$ increased unevenly, and the maximum value $13.3 \mathrm{kOe}$ is reached for $\left(\mathrm{Nd}_{0.8} \mathrm{Ce}_{0.2}\right)_{13} \mathrm{Fe}_{80} \mathrm{~B}_{5} \mathrm{Mo}_{2}$ alloy. The TEM results clearly indicated that the grain size is significantly reduced after the Mo addition. The systematic analysis indicates that there is the mixing of the pining and nucleation mechanisms of the investigated alloys though the former one is dominated varying with the composition. Finally, we may make a conclusion that the coercivity improvement in an appropriate scope of Mo content would be attributed to the synergistic effect of the refined grains, uniform microstructure and strong pinning. 

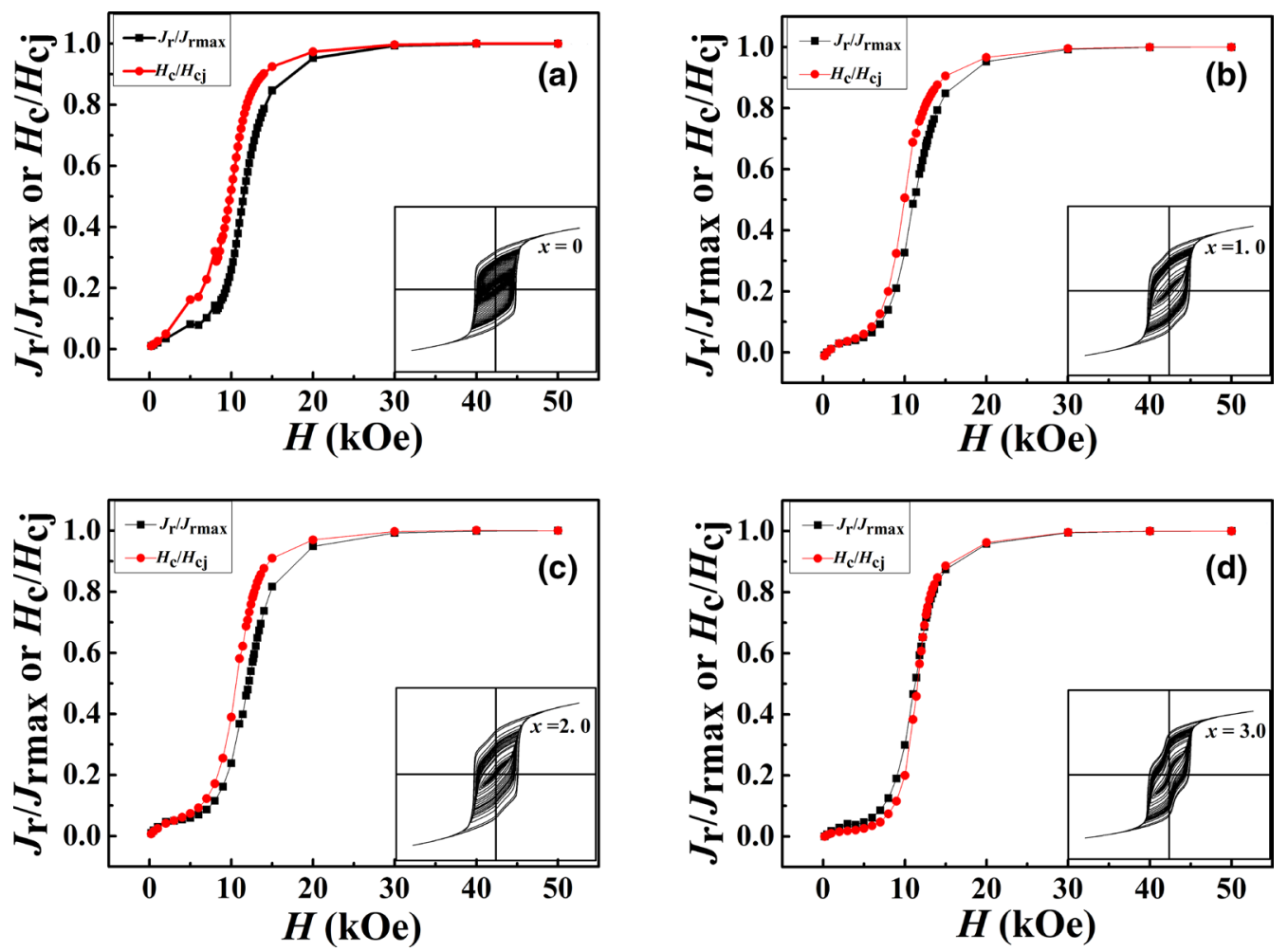

Fig. 7 Dependence of $J_{\mathrm{r}}$ and $H_{\mathrm{c}}$ on applied fields in the minor loops of $\left(\mathrm{Nd}_{0.8} \mathrm{Ce}_{0.2}\right)_{13} \mathrm{Fe}_{82-x} \mathrm{~B}_{5} \mathrm{Mo}_{x}$ alloys: a $x=0, \mathbf{b} x=1.0, \mathbf{c} x=2.0, \mathbf{d} x=3.0$

Acknowledgements This work was financially supported by the Jiangxi University of Science and Technology under excellent doctoral thesis cultivation project (No. 3105500035), the Science and Technology Program of Fujian Province (No. 2017T3001) and the National Natural Science Foundation of China (No. 51564037).

\section{References}

[1] J.J. Croat, J.F. Herbst, R.W. Lee, F.E. Pinkerton, J. Appl. Phys. 55, 2078 (1984)

[2] O. Gutfleisch, M.A. Willard, E. Brück, C.H. Chen, S.G. Sankar, J.P. Liu, Adv. Mater. 23, 821 (2011)

[3] M. Sagawa, S. Fujimura, H. Yamamoto, Y. Matsuura, J. Appl. Phys. 55, 2083 (1984)

[4] Y. Murakami, T.T. Sasaki, T. Ohkubo, K. Hono, Acta Mater. 101, 101 (2015)

[5] R.Q. Wang, X. Shen, Y. Liu, IEEE Trans. Magn. 52, 1 (2016)

[6] Q.Z. Jiang, Z.C. Zhong, J. Mater. Sci. Technol. 33, 1087 (2017)

[7] Q.Z. Jiang, M.L. Zhong, Q.C. Quan, W.K. Lei, Q.W. Zeng, Y.F. Hu, Y.P. Xu, X.J. Hu, L.L. Zhang, R.H. Liu, S.C. Ma, Z.C. Zhong, J. Magn. Magn. Mater. 444, 344 (2017)

[8] J.S. Zhang, W. Li, X.F. Liao, H.Y. Yu, L.Z. Zhao, H.X. Zeng, D.R. Peng, Z.W. Liu, J. Mater. Sci. Technol. 35, 1877 (2019)

[9] B.J. Ni, H. Xu, X.H. Tan, X.L. Hou, J. Magn. Magn. Mater. 401, 784 (2016)

[10] Q.Z. Jiang, W.K. Lei, L.K. He, Q.W. Zeng, S.U. Rehman, L.L. Zhang, R.H. Liu, S.C. Ma, Z.C. Zhong, J. Alloys Compd. 775, 449 (2019)

[11] E.J. Skoug, M.S. Meyer, F.E. Pinkerton, M.M. Tesema, D. Haddad, J.F. Herbst, J. Alloys Compd. 574, 552 (2013)
[12] A.K. Pathak, M. Khan, K.A. Gschneidner Jr., R.W. McCallum, L. Zhou, K. Sun, M.J. Kramer, V.K. Pecharsky, Acta Mater. 103, 211 (2016)

[13] X. Wang, M. Zhu, W. Li, L. Zheng, D. Zhao, X. Du, A. Du, Electron. Mater. Lett. 11, 109 (2015)

[14] A. Alam, M. Khan, R.W. McCallum, D.D. Johnson, Appl. Phys. Lett. 102, 042402 (2013)

[15] D. Li, Y. Bogatin, J. Appl. Phys. 69, 5515 (1991)

[16] X.B. Liu, Z. Altounian, M. Huang, Q. Zhang, J.P. Liu, J. Alloys Compd. 549, 366 (2013)

[17] E. Niu, Z.A. Chen, G.A. Chen, Y.G. Zhao, J. Zhang, X.L. Rao, B.P. Hu, Z.X. Wang, J. Appl. Phys. 115, 113912 (2014)

[18] S. Pandian, V. Chandrasekaran, J. Appl. Phys. 92, 6082 (2002)

[19] S.U. Rehman, Q.Z. Jiang, K. Liu, L.K. He, H.O. Yang, L.L. Zhang, L. Wang, S.C. Ma, Z.C. Zhong, J. Phys. Chem. Solids 132, 182 (2019)

[20] T.T. Sasaki, T. Ohkubo, Y. Takada, T. Sato, A. Kato, Y. Kaneko, K. Hono, Scr. Mater. 113, 218 (2016)

[21] L. Wang, Q.C. Quan, L.L. Zhang, X.J. Hu, S.U. Rehman, Q.Z. Jiang, J.F. Du, Z.C. Zhong, J. Appl. Phys. 123, 113904 (2018)

[22] Q.C. Quan, L.L. Zhang, Q.Z. Jiang, W.K. Lei, Q.W. Zeng, X.J. Hu, L. Wang, X. Yu, J.F. Du, G. Fu, R.H. Liu, M.L. Zhong, Z.C. Zhong, J. Magn. Magn. Mater. 442, 377 (2017)

[23] G. Rieger, J. Bauer, M. Seeger, H. Kronmüller, Nanostruct. Mater. 6, 953 (1995)

[24] S. Hirosawa, S. Mino, H. Tomizawa, J. Appl. Phys. 69, 5844 (1991)

[25] X.F. Shen, Y.Q. Wang, Z.T. Diao, X.F. Liu, J. Appl. Phys. 69, 3433 (1987)

[26] G. Rieger, M. Seeger, L. Sun, H. Kronmüller, J. Magn. Magn. Mater. 151, 193 (1995) 
[27] J.Q. Zhou, M.G. Zhang, Acta Metall. Sin.-Engl. Lett. 18, 557 (2005)

[28] J.J. Croat, J.F. Herbst, R.W. Lee, F.E. Pinkerton, Appl. Phys. Lett. 44, 148 (1984)

[29] J.F. Herbst, M.S. Meyer, F.E. Pinkerton, J. Appl. Phys. 111, 07A718 (2012)

[30] A.K. Pathak, M. Khan, K.A. Gschneidner Jr., R.W. McCallum, L. Zhou, K. Sun, K.W. Dennis, C. Zhou, F.E. Pinkerton, M.J. Kramer, V.K. Pecharsky, Adv. Mater. 27, 2663 (2015)
[31] A.K. Pathak, K.A. Gschneidner Jr., M. Khan, R.W. McCallum, V.K. Pecharsky, J. Alloys Compd. 668, 80 (2016)

[32] Q.Z. Jiang, M.L. Zhong, Q.C. Quan, J.S. Zhang, Z.C. Zhong, J. Alloys Compd. 688, 363 (2016)

[33] M. Zhang, Z. Li, B.G. Shen, F. Hu, J. Sun, J. Alloys Compd. 651, 144 (2015)

[34] G.C. Hadjipanayis, H. Kim, J. Appl. Phys. 63, 3310 (1988) 